\title{
História das Relações Internacionais no \\ Brasil: esboço de uma avaliação sobre a área
}

\author{
Norma Breda dos SANTOS ${ }^{1}$
}

\begin{abstract}
RESUMO: $\mathrm{O}$ artigo realiza uma reflexão metateórica sobre o campo da História das Relações Internacionais, avaliando a especificidade de seu programa de pesquisa e as características que tem assumido no Brasil. O texto compõese de duas partes principais. Na primeira, são feitas algumas considerações sobre a delimitação sociointelectual do campo da História das Relações Internacionais e sobre sua institucionalização. Na segunda, apresenta-se a trajetória desse campo de conhecimento no Brasil com a exposição de dois argumentos sobre a pesquisa realizada nas duas últimas décadas. O primeiro argumento é o de que os debates teóricos têm pouca repercussão na área. O segundo é o de que há uma relativa falta de contato entre os historiadores das relações internacionais do Brasil e aqueles que estudam a história do Brasil mais amplamente. Permeando discussões teóricas e metodológicas inescapáveis à reflexão da análise historiográfica, problematiza-se a evolução do debate e da produção nesse campo, que considera tanto a História Diplomática quanto as produções mais contemporâneas da História das Relações Internacionais do Brasil, bem como o ilustrativo tratamento temático e constitutivo da nacionalidade na escrita da história.
\end{abstract}

PALAVRAS-CHAVE: Historiografia; História das Relações Internacionais; História diplomática

[...] com a mão firme segura a esferográfica e acrescenta uma palavra à página, uma palavra que o historiador não escreveu, que em nome da verdade histórica não poderia ter escrito nunca, a palavra Não, agora que o livro passou a dizer é que os cruzados $N$ ão auxiliarão os portugueses a conquistar 
Lisboa, assim está escrito e portanto passou a ser verdade, ainda que diferente, o que chamamos falso prevaleceu sobre 0 que chamamos verdadeiro, tomou o seu lugar $[\ldots]{ }^{2}$

$\mathrm{Na}$ História do cerco de Lisboa, Raimundo Silva altera a narrativa da reconquista da península I bérica pelos cristãos. 0 revisor acrescenta um não à frase do historiador: "Os cruzados auxiliarão os portugueses a tomar Lisboa". Ou seja, em 1147, os cruzados não auxiliariam os portugueses a retomar Lisboa. O Cerco de Lisboa, um dos grandes feitos na memória histórica lusitana, é alterado pelo revisor sem mais nem porquê. Raimundo Silva fere a deontologia dos profissionais da revisão. Não há explicações para o ato ousado desse pacato e rigoroso corretor de textos alheios.

$\mathrm{Não}$ sabemos por que não convém a Raimundo a narrativa do historiador sobre a retomada de Lisboa. Sabemos, no entanto, que, no mesmo ano de 1147 foi retomada Santarém e que, com essas vitórias, a monarquia portuguesa alcança uma dupla façanha: diminui a pressão bélica moura sobre o interior da península Ibérica e estende a soberania territorial do reino português diante do reino vizinho espanhol. E, sobretudo, quanto ao "não" propriamente dito, podemos dizer que Raimundo quer fazer desaparecer da narrativa o auxílio dos cruzados, cujo papel histórico tem sido considerado importante na contenção militar da presença árabe na península I bérica.

A ação de Raimundo Silva pode ser vista como uma alegoria sobre a construção dos mitos fundadores da identidade nacional e sobre a construção do conhecimento histórico de maneira geral, para o qual contribuem elementos nacionais e elementos "exógenos", mais ou menos idiossincráticos. A problematização do fato histórico, amplamente presente na ficção de Saramago, faz-nos pensar sobre o papel, por exemplo, do etnocentrismo historiográfico europeu. 0 criador de Raimundo sustenta que dar uma posição marginal à península Ibérica na história européia foi uma estratégia britânica para gerenciar sua política de equilíbrio europeu. Com Saramago, os portugueses refazem a 
sua história, expulsando, sozinhos, os mouros, e afirmando gloriosamente seu Reino no século XII.

Mesmo sem o propósito de avançar aqui na reflexão propriamente dita sobre as injunções da nacionalidade como fenômeno subjacente à construção do conhecimento histórico, é importante ressaltar a relevância desse inescapável território sobre o qual toda pesquisa histórica se desenvolve. Assumindo o risco de insistir sobre o óbvio, vale registrar que:

Nation et histoire ont certes avancé main dans la mais [...]. L'histoire, celle des historiens s'est imposée un peu par tout au cours du XIXe siècle alors même que la nations apparaissait comme l'horizon indépassable de toute histoire passée, présente et à venir. De ce fait massif faudrait-il simplement conclure que I'histoire, comme institution, ne pouvait échapper (l'aurait-t-elle voulu) à la 'tyrannie' du national, qui l'a modelée en profondeur?

$E$ se nação e nacionalidade são constitutivas do conhecimento histórico, e se o Estado-nação, ainda que não único, é 0 ator privilegiado da história das relações internacionais, este é, sem dúvida, um campo de estudos em que o fenômeno da nacionalidade se manifesta de forma privilegiada. Ao tratar da questão, Carr menciona as instruções - que hoje nos parecem pitorescas - que Lord Acton deu aos seus colaboradores, no final do século XIX, ao organizar a primeira, extensa e "definitiva" Cambridge M odern H istory:

[...] nosso Waterloo deve ser tal que satisfaça franceses e ingleses, alemães e holandeses da mesma maneira; que ninguém possa dizer sem examinar a lista de autores, onde 0 bispo de Oxford parou de escrever e onde Fairbairn ou Gasquet, Libermann ou Harrison continuaram. ${ }^{4}$

Obviamente, a orientação de Acton não gerou 0 resultado buscado.

0 presente texto tem o propósito de refletir sobre a especificidade da H istória das Relações Internacionais e sobre as características que a pesquisa neste campo tem adquirido no 
Brasil. 0 texto compõe-se de duas partes principais. $\mathrm{Na}$ primeira, fazemos algumas considerações acerca do que tem sido entendido como o campo da História das Relações Internacionais e sobre sua institucionalização. Na segunda, tratamos da trajetória desse campo de conhecimento no Brasil e apresentamos dois argumentos sobre a pesquisa realizada nas duas últimas décadas. 0 primeiro argumento é o de que os debates teóricos têm pouca repercussão na área. 0 segundo é 0 de que há uma relativa falta de contato entre os historiadores das relações internacionais do Brasil e aqueles que estudam a história do Brasil mais amplamente.

\section{O ENCONTRO ENTRE CLIO E LEVIATÃ}

A História Diplomática tradicional é provavelmente um dos campos em que o elogio da nacionalidade aparece da forma mais evidente, daí a desqualificação que tem sofrido esse campo há várias décadas e o aparecimento da História das Relações Internacionais, que é proposta como mais abrangente e ciosa das complexidades inerentes a seu objeto, e sobretudo, como não-apologética da ação dos homens de Estado e dos atos de governo. No entanto, "international history is a new field with an old pedigree", como observa Zara Steiner (1997) em seu artigo "On W riting International H istory: Chaps, M aps and M uch M ore", ${ }^{6}$ sugestivo título para tratar das "esferas de competência", por assim dizer, da História Diplomática e da História das Relações Internacionais. Steiner lembra, com razão, que a primeira tem a seu crédito pesquisas históricas de grande valor. Além disso, mostra que há muito a História Diplomática tem se preocupado com a abertura da "caixa preta", que abriga as atividades dos Estado e dos governos, incorporando novas problemáticas e recursos documentais. $\mathrm{E}$, acrescentemos, no século XIX, quando o conhecimento histórico aparece como disciplina científica, a História Diplomática tinha lugar de prestígio. Basta lembrarmos que Ranke propunha uma História com três dimensões principais: o estudo dos acontecimentos internos das grandes potências 
européias, dos movimentos coletivos e forças que resultam da experiência institucional, religiosa e social, e das relações entre os Estados, dando ênfase ao confronto entre estes. 0 conhecimento histórico não "estacionou" em Ranke. A História Diplomática tampouco.

Portanto, parece abusivo afirmar que a História Diplomática atualmente confunda-se com a história oficial, ainda que, entre outras coisas, ela possa fazê-lo. Com o risco que toda comparação significa, vale aqui a referência, por exemplo, à "reabilitação" da H istória Política nas últimas duas décadas. Foi esse o objetivo da publicação da coletânea Por uma história política, organizada por René Rémond (1996): fazer a defesa da nova História Política. O livro retraça a trajetória da História Política na França, desde o seu apogeu no século XIX, quando esse campo também se confunde com a profissionalização dos estudos históricos e busca a obtenção do status de ciência, passando pelo seu quase ostracismo no momento da prevalência da Escola dos Anais, sob a acusação de se interessar somente pelas minorias privilegiadas, e sua renovação e enriquecimento nos anos 1980, com novas abordagens, objetos e problemas. 0 texto de Steiner mostra os similares altos e baixos da História Diplomática. Simplificadamente: ascensão e afirmação no final do século XIX e descrédito com a preponderância dos Annales. ${ }^{8}$ Diferentemente da História Política, porém, a História Diplomática, com este rótulo, parece não ter conseguido sua reafirmação na academia e assumiu, assim, uma nova designação - História das Relações Internacionais - , embora nada haja de escusável em um campo de pesquisa histórica que aponta para a relevância da documentação diplomática e que é importante, sim, que esse manancial documental seja estudado de maneira crítica. ${ }^{9}$

Seja como for, vários dos questionamentos a que se submete a História Diplomática são comuns à História das Relações Internacionais: a pesquisa histórica passa da ênfase ao macro à incorporação do micro; os amplos processos e estruturas, típicos dos A nnales, devem dialogar com o menor e 
- local; passa-se pelo cultural turn, pelo linguistic turn. Entretanto, como essas perspectivas que incluem estruturas e processos definidos por uma lógica de "baixo para cima" podem conviver com a produção da História Diplomática/História das Relações Internacionais, em que 0 Estado não deixa de ter centralidade?

Não há uma resposta simples para essa questão complexa. Georg I ggers faz al gumas considerações sugestivas a propósito do problema ao referir-se às conseqüências do colapso da União Soviética e ao fim da Guerra Fria, que, segundo 0 autor, não podem ser ignorados: "the condition of contemporary world [pós-1989] made inescapable large-scale investigations of transformations that present-day societies are undergoing". ${ }^{10}$ Lembra, por exemplo, as interpretações e modelos propostos em $O$ Fim da História (1992), de Francis Fukuyama, ${ }^{11}$ e 0 Choque de Civilizações (1996), de Samuel Huntington. ${ }^{12}$ Para Fukuyama, o fim da União Soviética marcava a propagação da cultura do consumo em escala mundial e a vitória do Ocidente e do mundo capitalista, enquanto Huntington apontava para a importância das culturas locais como motivadoras de alianças e choques no mundo contemporâneo, sendo que a sobrevivência do O cidente dependeria da propagação dos valores americanos às demais civilizações. ${ }^{13}$ Embora o valor historiográfico e teórico desses trabalhos tenha sido questionado por inúmeros historiadores, haja vista suas implicações políticas e sua natureza especulativa, esses estudos tiveram, de maneira geral, enorme repercussão. Por vias opostas - 0 modelo de modernização do estudo de Fukuyama rapidamente revelou-se ilusório pelas manifestações do "velho" nacionalismo e do fundamentalismo religioso da última década e meia, e o trabalho de Huntington faz do multiculturalismo dos cientistas sociais e historiadores "a cancer that threatens to destroy the West" -, mostrou-se que "[w] hat is needed in its stead is a broad historical approach that takes both cultural and institutional aspects into consideration" ${ }^{14}$ 
0 debate segue, portanto, e o conhecimento histórico sempre se beneficia com 0 diálogo entre diferentes perspectivas, diferentes "escalas"; a ênfase no macro é claramente relevante, até porque negá-lo implicaria simplesmente alienação de determinados processos aos quais não escapamos. Na história das relações internacionais, em que estes são privilegiados, são particularmente bem-vindos os temas e metodologias voltados para analisar as representações, as percepções, as idéias, os movimentos da sociedade e das comunidades nacionais, a busca da identificação de forças mentais e suas manifestações, as formas com que os homens e as sociedades se interpretam e se identificam.

A institucionalização da história das relações internacionais firma-se a partir da década de 1970, com a criação de departamentos, periódicos, associações de pesquisadores, etc.: ${ }^{15}$

[a]lthough the subject now stretches to include the domestic origins of foreign policy, and economic or cultural movements as well as classical statecraft, it still quite definitely focuses on how governments have interacted, particularly during the great political events that have decided the fate of millions, such as the outbreak of the First War or the Conference at Yalta. Moreover, those working in International Relations draw readily on historical writing about events within the confines of the state such as about nationalism in specific countries or domestic conflict over foreign policy issues. ${ }^{16}$

E sobre a questão há dois aspectos que merecem ainda atenção. 0 primeiro é o de que, embora a institucionalização da História das Relações Internacionais aconteça no mundo acadêmico na década de 1970, precedem de muito tempo os trabalhos de Pierre Renouvin e a criação, em 1935, do Instituto Pierre Renouvin, na Sorbonne. ${ }^{17}$ M esmo que o Instituto Pierre Renouvin tenha perdido um bocado de seu élan ou, mais provavelmente, a academia francesa tenha perdido um bocado de sua influência na área quando comparada à marcante 
preponderância anglo-saxã atual, há que ser lembrado, como afirma René Girault, ${ }^{18}$ que Pierre Renouvin ...

[...] fit accomplir une révolution épistémologique de même ampleur que celle des Annales à un domaine particulier de I'histoire, celui des relations entre les États ou entre les hommes séparés par des frontières.

De fato, Pierre Renouvin representa a transição entre a História Diplomática tradicional e a História das Relações Internacionais. Com o conceito de "forças profundas", Renouvin enfoca não somente o papel do Estado e a pesquisa nos arquivos diplomáticos, mas também a história econômica e social, a história das idéias e das instituições. Escreveu com Jean-Baptiste Duroselle, seu sucessor no Centro Pierre Renouvin, Introduction à l'Histoire des Relations Internationales, publicado em 1964. Duroselle, por sua vez, publicou outra obra dedicada à metodologia, Tout Empire Périra, em 1981 (publicado em português em 2000). René Girault e Robert Frank sucederam Duroselle na direção do instituto.

Outra questão diz respeito à conexão existente entre as áreas de Relações Internacionais e de História das Relações Internacionais. A institucionalização acadêmica do campo de Relações Internacionais data do final da Primeira Guerra M undial e surge com a preocupação precípua de compreender os fatores que engendram a guerra e 0 que fazer para prevenila. Em 1919, na Universidade de Gales, em Aberystwyth, foi criado o Departamento de Política Internacional, e em 1936, nele passa a lecionar E. H. Carr, que deixa o Foreign Office, onde havia trabalhado por vinte anos. Carr será um dos mitos fundadores que orientarão o trabalho do departamento ${ }^{19}$ e, sem dúvida, da nova disciplina. Seu Vinte Anos de Crise, publicado em 1939, pouco após a invasão da Polônia por Hitler, estabelece 0 início do debate teórico na nova disciplina. ${ }^{20}$

Em sua origem, o campo de Relações Internacionais esteve marcado pela História, além do Direito Internacional e 
da Ciência Política. ${ }^{21}$ As interconexões entre as disciplinas H istória das Relações Internacionais e Relações Internacionais são, portanto, notórias. 0 campo de interesse da última, que se ampliou para contemplar outros atores além do Estado e fenômenos que se dão fora do âmbito estatal, tem repercussões importantes na primeira. Na realidade, tratar da produção histórica sobre as relações internacionais implica considerar, no mínimo, a importante aproximação entre a História, o Direito Internacional e a Ciência Política, e cada vez mais também os estudos da Economia. ${ }^{22}$

Por características próprias da institucionalização da área de Relações Internacionais no Brasil, que segue 0 preponderante padrão norte-americano, em que Ciência Política e Relações Internacionais são áreas acadêmicas de um mesmo departamento, ${ }^{23} 0$ diálogo dos historiadores das Relações Internacionais acontece em boa medida com os especialistas de Relações Internacionais com formação "politológica". Conseqüentemente, propor uma reflexão sobre a produção da História das Relações Internacionais no Brasil implica considerar a "cross-fertilization" com os estudos de Relações Internacionais, em particular, conforme a expressão de Colin e Miriam Elman, organizadores do Bridges and Boundaries: Historians, Political Scientists and the Study of International Relations. ${ }^{24}$

Qual a especificidade de um campo em relação ao outro? Podemos mencionar a distinção entre as pesquisas de orientação idiográfica e as de orientação nomotética: a primeira referindo-se aos estudos de História; a segunda, aos de Ciência Política; aquela adotando o estilo narrativo; esta, a explicação analítica. Ainda que esse critério possa ser útil pedagogicamente, parece atropelar várias questões nem um pouco simples de serem definidas e que embutem uma importante discussão de natureza epistemológica que tem a ver com o que foi chamado de "crise da história", "crise do ofício do historiador", uma vez que, atualmente, pensar na História como uma disciplina completamente distinta não é praticamente mais aceito. $^{25}$ 
N este artigo, utilizaremos a distinção proposta por Colin e M iriam Elman, já que nos remete à maneira pela qual os próprios pesquisadores dessas áreas - História das Relações Internacionais e Relações Internacionais - se percebem e se identificam. Neste sentido, antes de mais nada tenhamos em mente que há, sim, muita similaridade entre o que fazem os historiadores e os cientistas políticos que estudam as relações internacionais. Eles não diferem, por exemplo, quando esperam que o estudo do passado possa auxiliar na resolução de problemas atuais. Além disso, a narrativa histórica não prescinde de teoria, assim como a teoria das relações internacionais necessita dos fatos históricos para serem avaliadas. $^{26}$

Assim, aparecem duas questões a partir das quais podemos apontar a distinção entre 0 que fazem os historiadores e os cientistas políticos, a qual, entendemos, deva ser considerada frouxamente. Em primeiro lugar,

[... ] political scientists are more likely to look to the past as a way of supporting or discrediting theoretical hypotheses while historians are more likely to be interested in past international events for their own sake. Although political scientists might turn to the distant past, the study of "deep" history is relevant to their research objectives only insofar as it enables them to generate, test, or refine theory. By contrast for the historians the goal of theory building and testing is secondary - "the past interests historians for itself'.

Em segundo lugar,

political scientists tend to reward new and explicit theoretical work over a meticulous culling of archives, and are more likely to favor scholarship that is parsimonious; that is, research that demonstrate how only a few explanatory variables can account for a wide range of phenomena. Historians show a greater tolerance for overdetermined explanations and a great affinity for scholarship that explains international and foreign policy outcomes via multiple sufficient causation or equifinality. 
Nessa distinção, considerada aqui por seu valor instrumental, é apontado, ainda mais resumidamente, que: (1) o passado interessa mais ao cientista político pelo suporte que oferece para o estabelecimento da teoria, enquanto para 0 historiador, o passado em si é o que interessa; (2) o cientista político busca o estabelecimento de poucas variáveis que possam explicar o maior número de fenômenos possível, e o historiador dá menor atenção à parcimônia no estabelecimento das causalidades. Ou ainda: o cientista político preocupa-se mais com o conteúdo explicativo generalizante da política internacional e externa, enquanto 0 historiador preocupa-se menos com a generalização, dando maior ênfase aos elementos empíricos e buscando causalidades múltiplas para entender a política internacional e externa. ${ }^{28}$

HISTÓRIA DAS RELAÇÕES INTERNACIONAIS DO BRASIL

Embora exista uma razoavelmente prolífica produção acadêmica que trata da historiografia sobre as relações internacionais do Brasil, ${ }^{29}$ quando comparada ao conjunto dos trabalhos sobre a historiografia brasileira - que se torna mais numeroso a partir da década de 1970 e que dá um salto qualitativo importante na década de 1990, com um esforço de profissionalização ${ }^{30}$-, a proporção dessa produção parece modesta. Em outras palavras: muitos trabalhos têm sido publicados sobre a historiografia brasileira, mas, proporcionalmente, no âmbito dessa produção, são poucos os trabalhos que se dedicam à historiografia das relações internacionais do Brasil. Além disso, e sobretudo, os trabalhos mais amplos, que se propõem a abordar temas diversos da historiografia brasileira, não têm dedicado espaço ao estudo das relações internacionais do Brasil. 0 estudo sobre essa área é, em geral, realizado por historiadores que têm dialogado mais regularmente com a área de Relações Internacionais do que com campos especificamente históricos. ${ }^{31}$ 
A diminuição mencionada torna-se ainda mais notória quando lembramos os trabalhos seminais de José Honório Rodrigues. De fato, além de ter publicado, em 1949, Teoria da História do Brasil, "a primeira obra a merecer cabalmente a qualificação de obra de historiografia brasileira", ${ }^{32}$ em que dedica amplo espaço a aspectos ligados às relações internacionais do Brasil, Rodrigues é também considerado 0 "pioneiro na análise de política externa" do Brasil. ${ }^{33}$

Por outro lado, na década de 1970 e nos primeiros anos da década seguinte, período marcado pela publicação de vários trabalhos de análise historiográfica que se tornaram referenciais, o tema não aparece particularizado. Assim, não há como dimensionar a importância da História das Relações Internacionais por meio desses trabalhos. Foram especialmente objeto de nossa atenção os trabalhos de J. R. do Amaral Lapa, A História em Questão: H istoriografia Brasileira Contemporânea, publicado em 1976; de Carlos Fico e Ronald Polito, A H istória no Brasil (1980-1989), publicado em 1992; 0 artigo de Fico, "Teses e dissertações de história defendidas em 1995"; o livro organizado por Marcos Cezar de Freitas, H istoriografia Brasileira em Perspectiva, publicado em 1998, e o mais recente deles, de José Jobson Arruda e José Manuel Tengarrinha, H istoriografia Luso-Brasileira Contemporânea, de 1999.

Esses estudos mostram a reformulação das áreas temáticas dos estudos históricos como resultado da recepção no Brasil, ao longo dos anos, de novas abordagens. Assim, recuam a história econômica e a história social, e ganham espaço a história da cultura, do cotidiano, da sexualidade, com temas típicos: a história da mulher, da educação, do trabalho, da família, das crianças. Em uma palavra: o macro e o micro são estudados e relacionados. Além disso, como Fico e Polito (1996) notam,

[...] [0]s impasses teóricos e a renovação temática vividos por nossa disciplina talvez expliquem aquilo que poderíamos chamar de "diluição das abordagens metodológicas estritas", isto é, há um bom número de trabalhos que não são 
exclusivamente de história social, história política ou história cultural, mas que - num possível esforço de renovação - se situam em áreas de fronteira.

É plausível concluir que a História das Relações Internacionais não se tenha beneficiado amplamente com a existência dessa tendência, mas também temos de lembrar que muitas das pesquisas que tratam de temas dessa área aparecem em outros "escaninhos". A H istória Política é um exemplo, em que a chamada "questão nacional", na época da Independência e do Império do Brasil, tem sido dos temas mais fecundos. ${ }^{35} \mathrm{E}$ ainda, com certeza, a globalização bateu à porta do historiador e as pesquisas com temas típicos da História das Relações Internacionais foram objeto de estímulo.

De toda forma, as linhas de pesquisa ou áreas de concentração dos programas de pós-graduação ilustram bem a grande tendência referida. ${ }^{36} \mathrm{O}$ Programa de Pós-Graduação em H istória da Universidade de Brasília, caso único, teve, de 1976 a 2002, uma área de concentração em História das Relações Internacionais, área que faz parte atualmente do Instituto de Relações Internacionais (Irel) da mesma universidade. ${ }^{37}$ A título meramente indicativo, parece interessante o seguinte dado: das 168 dissertações defendidas de 1978 ao final de 2002, 53 estavam ligadas à área de concentração de História das Relações Internacionais, praticamente $1 / 3$ do total, sendo que, no período, o Programa esteve organizado sempre em três áreas de concentração.

Afora essas observações de cunho comparativo, há que ser notada a progressiva institucionalização e profissionalização da pesquisa sobre História das Relações Internacionais no Brasil e o abandono progressivo da História Diplomática tradicional. Essa tendência, que se esboça nos anos 1970, faz eco no estabelecimento da pós-graduação no Brasil. A propósito, Gelson Fonseca Júnior indica que:

[...] ao correr da década de 70 os temas diplomáticos brasileiros transformam-se em temas de estudos acadêmicos; foram 'absorvidos' pela Academia. Criou-se uma 
especialização em política externa brasileira na universidade (no Brasil e no mundo) e, com isto, conformou-se um novo interlocutor em nosso processo de formulação diplomática. Numa comparação entre a produção intelectual sobre a política externa nos anos 50 e 60 com a dos anos 70, o que ressalta é o profissionalismo, a 'scholarship' destes escritos. ${ }^{38}$

Além disso, há que se mencionar um fenômeno em sentido inverso, ou seja, uma certa "academização" dos estudos realizados pelos diplomatas brasileiros. Essa academização resulta do interesse pessoal de alguns diplomatas pela pesquisa ou está ligada à própria formação do(a)s diplomatas e à sua ascensão profissional. Para serem candidatos a embaixador(a), o(a)s diplomatas devem seguir 0 Curso de Altos Estudos (CAE), no final do qual apresentam uma tese relativa a tema de interesse da diplomacia. Várias dessas teses foram e estão sendo publicadas. Além disso, desde 2004, os aprovados no concurso de admissão para a carreira diplomática são automaticamente inscritos no mestrado profissionalizante em diplomacia.

Com relação ao período anterior à década de 1970, podemos primeiramente falar dos "historiadores diplomatas", como faz Paulo Roberto de Almeida, ${ }^{39}$ para nos referirmos à história diplomática escrita pela elite intelectual, que muitas vezes se confundia com a governamental. Historiadores como Duarte da Ponte Ribeiro, Varnhagen, barão do Rio Branco, Joaquim Nabuco, Oliveira Lima e Pandiá Calógeras, ${ }^{40}$ nomes que, de fato, ilustram essa superposição entre a atividade de pesquisa sobre a história diplomática brasileira e a prática dessa diplomacia. Antes de chegarmos aos anos 70, temos um grupo intermediário de pesquisadores, entre os quais sobressaem Hélio Vianna e Delgado de Carvalho - "autores intermediários". ${ }^{41}$

Da geração de pesquisadores acadêmicos que surgem na década de 1970, Fonseca Júnior elenca, em sua análise, o trabalho de vários brasileiros e estrangeiros. Entre os brasileiros, são citados notadamente cientistas sociais como Maria Regina Soares de Lima, Celso Furtado, Alexandre 
Barros, Otavio Ianni e Carlos Estêvão Martins. Poucos são os historiadores, como Moniz Bandeira, Roberto Gambini e Gerson Moura.

Tanto Fonseca Júnior como Almeida chamam a atenção para a modéstia na quantidade dos trabalhos de síntese sobre as relações internacionais do Brasil. De fato, os trabalhos desse gênero são poucos e bastante conhecidos: de Pandiá Calógeras (1927-1928), sobre o período imperial; de Hélio Vianna (1961), de Delgado de Carvalho (1959), e o mais recente, de Amado Luiz Cervo e Clodoaldo Bueno (1992 e edição revisada de 2002).

O trabalho de Cervo e Bueno é uma síntese bem elaborada da política externa brasileira desde 1822 até nossos dias. Pela consulta de um elenco enorme de estudos sobre os mais diversos temas, incluindo aí teses de doutorado e dissertações de mestrado, a obra corresponde, em boa medida, ao estado da arte sobre a política externa brasileira, "costurada" conforme a compreensão e interpretação dos autores, que elaboram uma periodização que passou a ser bastante utilizada por muitos especialistas. Podemos considerar, assim, essa consolidação do conhecimento na área como trabalho de uma História Diplomática não-tradicional, pois, embora o Estado e a documentação diplomática tenham lugar privilegiado, entram também em conta os processos políticos, econômicos e sociais - as forças profundas, conforme a designação do historiador Pierre Renouvin, cuja orientação metodológica é levada em conta pelos autores.

Explicitada está, portanto, a grande contribuição que entendemos ser a obra de Cervo e Bueno para o campo de estudo da História das Relações Internacionais do Brasil. De toda forma, algumas observações críticas sobre esse trabalho merecem destaque. Primeiramente, devem ser registrados os comentários de Paulo Roberto de Almeida sobre um aspecto da obra:

Um único problema suscita essa síntese [...]. Ele se refere a uma questão de ordem propriamente metodológica, a saber, o monitoramento da política exterior segundo a visão hegeliana, 
[...] acompanhando o desenrolar da História segundo uma idéia-guia, não necessariamente preconcebida, mas indisfarçavelmente concebida a posteriori, no caso, a busca incessante do desenvolvimento econômico e o papel do Estado nesse processo $[. . .]^{43}$

Para além dessa questão parece haver outra, anterior e ainda mais importante: a não adequação da obra à abordagem que Cervo e Bueno invocam. Ou seja, os autores, ao mesmo tempo em que recorrem a uma metodologia que privilegia as causas múltiplas e os diferentes níveis analíticos para compreender a inserção internacional do Brasil e a política exterior brasileira, identificam Estado e nação e confundem 0 discurso diplomático do Itamaraty com a própria política externa brasileira. Assim, a história das relações internacionais dos autores não está, de fato, situada num quadro da história geral, como diria Renouvin, de história econômica e social, história das idéias e das instituições; por outro lado, o Estado é identificado com uma nação unitária, não multifacetada nem problematizada. Em vários trechos da obra os autores fazem referência ao Estado brasileiro conformando-se com os interesses da "nação".

Essa questão pode ser desdobrada em duas outras, subjacentes, que, pela importância do trabalho de Cervo e Bueno, provavelmente dizem respeito à boa parte dos trabalhos de brasileiros identificados como de História das Relações Internacionais do Brasil. A primeira questão diz respeito a uma certa impermeabilidade da História das Relações Internacionais no Brasil ao debate teórico e metodológico. A segunda tem a ver com a incipiente interlocução entre os historiadores das relações internacionais e seus pares que se dedicam mais diretamente à história do Brasil.

HISTÓRIA DAS RELAÇÕES INTERNACIONAIS E HISTÓRIA DO BRASIL 
No Brasil, possivelmente por causa da institucionalização e do adensamento relativamente tardio da pesquisa acadêmica na área de História das Relações Internacionais, não se percebe ainda o surgimento de um debate claramente estabelecido entre teses interpretativas, ainda que a diversidade de interpretações obviamente exista. 0 que chama mais a atenção, no entanto, é a modesta interlocução entre os historiadores das relações internacionais e seus pares que se dedicam mais diretamente à História do Brasil. Sobre esse caminho de mão dupla, interessa-nos apontar apenas alguns aspectos de uma de suas vias: os prováveis benefícios para a História das Relações Internacionais de um contato mais freqüente e próximo com a História do Brasil, cujos desenvolvimentos certamente iluminariam as interpretações da História das Relações Internacionais do Brasil. Para tratar da questão, citaremos um exemplo que consideramos muito significativo.

A Revolução de Trinta tem sido considerada o marco essencial da história brasileira do século XX. A grande ênfase da historiografia em apontá-la como um marco de ruptura e um evento inaugurador de uma nova era, politicamente moderna e industrializante, resultou em uma desqualificação dos processos históricos anteriores. A história da Primeira República foi, assim, marcadamente narrada e analisada com linearidade e simplificação, fazendo que passasse a ser tida como uma "Idade M édia" brasileira, elucidando, por fim, relativamente pouco da complexidade do período 1889-1930.

Ao exagerar nas tintas, essa interpretação, claramente predominante na historiografia até as duas últimas décadas, não deixou de contaminar as interpretações sobre a história da política externa brasileira no período, nela projetando "vícios" da República do "café com leite". A "ornamentalidade" e a "instrumentalidade", termos utilizados para caracterizar o período anterior e o período posterior à Revolução de Trinta, é manifestação desse fenômeno. 0 prestígio estaria identificado com a dimensão ornamental, enquanto o desenvolvimento 
econômico, como vetor da política externa, seria sinônimo de uma dimensão de instrumentalidade. ${ }^{44}$

Sobre a chamada política do "café com leite" da "República Velha", a pesquisa histórica, desde a década de 1980, tem realizado importante revisão. 0 período, por muito tempo entendido como pouco mais do que uma sucessão monótona de oligarquias paulistas e mineiras na presidência da República, mostrou-se, muito pelo contrário, caracterizado por alianças políticas em constante redefinição.

Obras particularmente iluminadoras sobre a questão são, em primeiro lugar, o já bastante conhecido e citado trabalho de Edgar De Decca, O Silêncio dos Vencidos (1981), ${ }^{45}$ em que 0 autor faz uma reflexão historiográfica, mostrando, entre outros aspectos, que a periodização - 0 antes e o depois de 30 - engendra um discurso político e histórico que faz desaparecer atores e acontecimentos decisivos para a fundação do que se convencionou chamar de Revolução de Trinta. 0 trabalho de Cláudia Maria R. Viscardi, por sua vez, 0 Teatro das Oligarquias: Uma Revisão da "Política do Café com Leite" (2000), ${ }^{46}$ realiza uma leitura inovadora sobre a Primeira República no Brasil, mostrando que a hegemonia das elites políticas de M inas Gerais e São Paulo esteve marcada por uma permanente instabilidade e a inexistência de alianças ou regras duradouras entre os dois Estados. $E$, finalmente, os historiadores econômicos também têm contribuído para problematizar as interpretações sobre a história do Brasil do século XX. ${ }^{47}$

Em artigo recente, ${ }^{48}$ tratamos da saída do Brasil da Liga das N ações em 1926, ao não obter um assento permanente no Conselho da organização internacional. Esse episódio tem sido qualificado pela historiografia brasileira como um grande "fiasco" da diplomacia brasileira, enfatizando a idéia de que 0 governo do presidente Artur Bernardes (1922-1926) monopolizou a responsabilidade pela crise de março de 1926 na Liga. Ao contrário dessa interpretação, buscamos mostrar que, para compreender a participação brasileira na liga das Nações, deve-se levar em consideração os problemas 
institucionais que a liga apresentava, bem como aspectos da política européia, sobretudo a atuação da França e da GrãBretanha. N esse sentido, apontamos que, se se pode falar em fiasco, há que se falar de um fiasco mais amplo, que tem a ver com a tentativa frustrada de se criar, no período pós-Versalhes, uma nova ordem internacional. Além disso, se a interpretação de que o Brasil na Liga das Nações buscava prestígio está correta, deve, no entanto, ser posta em perspectiva. A diplomacia brasileira daquele momento faz eco aos valores e padrões imperantes no começo do século XX, a qual está impregnada de valores do século XIX. A noção de prestígio guia em boa medida a política européia, que irradia valores para o Novo Mundo. Não considerar esse aspecto seria submergir no anacronismo. Finalmente, a caracterização da diplomacia brasileira daquele período como ornamental, pela historiografia brasileira, em contraposição à instrumentalidade que adquirirá no período pós-Revolução de Trinta, deve ser revista, uma vez que está fortemente "contaminada" por discurso político e histórico revolucionário, que superdimensiona o pós-Trinta e desqualifica o período anterior, em que a diplomacia brasileira se encaixaria nos ditames "liberais" e pouco voltados para os interesses nacionais "autênticos".

HISTÓRIA DAS RELAÇÕES INTERNACIONAIS E TEORIA DA HISTÓRIA

N ovas temáticas e novas opções metodológicas não têm penetrado de maneira significativa no campo da História das Relações Internacionais no Brasil, embora tenham tido grande repercussão junto à maioria dos historiadores brasileiros. A pesquisa ocupada em estudar as percepções, os movimentos de idéias e suas manifestações, a maneira como os homens se interpretam e se identificam, já claramente contempladas pela pesquisa histórica de forma geral, penetra, por exceção, na pesquisa histórica sobre as relações internacionais do Brasil. 
Alexandra de M ello e Silva publicou dois trabalhos que tratam da importância de se avaliar o impacto das idéias na formulação da política externa brasileira e de se reconstruir as principais crenças e idéias presentes no discurso diplomático brasileiro, identificando as concepções sobre a natureza e a estrutura do sistema internacional, sobre o modo de inserção que teria o País no sistema internacional e sobre a identidade nacional e sua manifestação externa. Em "O Brasil no Continente e no M undo: Atores e Imagens na Política Externa Brasileira Contemporânea" (1995) e em "Idéias e política externa: a atuação brasileira na Liga das Nações e na ONU" (1998), a preocupação da autora é de compreender as variáveis que, dentro e fora do Estado informam a concepção de sua política externa. Conforme a autora, a institucionalização tardia da pesquisa universitária fez que esta tendesse a privilegiar as dimensões normativas e prescritivas, sem dar a devida atenção à dimensão cognitiva da formulação da política externa brasileira contemporânea.

Também merece atenção 0 trabalho de Roberto Abdenur, "A Política Externa Brasileira e o 'Sentimento de Exclusão'" (1994). ${ }^{49}$ O autor trata do impacto do que denomina "sentimento" ou "síndrome" de exclusão, segundo o autor, presente na cultura brasileira, e do seu impacto na política externa do Brasil. Para Abdenur, essa tendência à auto-imagem negativa deitaria raízes em nossa formação cultural, constatada, por exemplo, na obra de Sérgio Buarque de Holanda. Manifestação do mesmo fenômeno seria encontrada em "período muito recente de nossa história, [em que] assistimos a um recrudescimento das formas mais negativas de sentimentos autodepreciativos em relação ao Brasil. Em certo momento, o Brasil foi tomado por um verdadeiro 'fetichismo primeiro-mundista'". ${ }^{50}$ Assim, com 0 diagnóstico, Abdenur busca apontar al gumas distorções que se tornaram lugar-comum sobre a posição do Brasil no mundo.

Finalmente, outro trabalho que merece atenção é o livro de Luís Cláudio Villafañe dos Santos, 0 Brasil entre a Europa e a América: 0 Império e 0 Interamericanismo (2004). ${ }^{51}$ São 
numerosos os estudos sobre o interamericanismo no século XIX, que têm sido marcados pela abordagem jurídica ou histórica de cunho descritivo. Dentre eles, alguns tratam das posições do Império brasileiro com relação às iniciativas interamericanistas, de matriz bolivariana ou estadunidense. Assim, a novidade do trabalho de Santos é empreender um estudo que permita ao leitor compreender a persistente desconfiança da elite brasileira com relação aos encontros interamericanos ao longo de sete décadas de Império. Essa persistência é explicada pela natureza de legitimação do Estado brasileiro, que contrasta com a dos vizinhos. De fato, 0 princípio da legitimidade dinástica é o que dá sentido primordialmente à construção da identidade política da elite brasileira e é o que assegura a unidade do vasto território, sobretudo quando comparada à fragmentação vivida pelas excolônias espanholas vizinhas, que rompem com 0 antigo regime e custam a apaziguar seus conflitos. Os brasileiros espelham-se na Europa, na cultura "civilizada", distinta da de seus vizinhos "anárquicos".

Se a idéia de civilização propagada pelas elites brasileiras era, estranhamente, compatível com a escravidão e a exclusão da maioria da população do corpo político da nação, a adoção do nacionalismo e da cidadania como fonte de legitimidade do Estado era potencialmente explosiva em uma sociedade fracamente integrada regionalmente e com uma população composta em grande parte por escravos. ${ }^{52}$

\section{CONCLUSÃO}

0 propósito deste artigo foi o de refletir sobre o campo da História das Relações Internacionais e, particularmente, começar a realizar um balanço sobre os avanços e eventuais fragilidades que a pesquisa nessa área tem manifestado no Brasil. Um ponto a destacar, logo de início, é a questão da nacionalidade como profícuo eixo de análise, que muito tem a oferecer para se compreenderem as expressões que adquire 0 conhecimento histórico em comunidades nacionais diferentes, 
mesmo considerando-as em sua distinção imperfeita e em sua heterogeneidade constitutiva. Ou seja, façamos o "nosso Waterloo" tal que problematize o interesse eleito como nacional, o processo de escolha desse interesse, as idéias que inspiram nossos "generais" e demais decisores, a dimensão simbólica de nossas lutas - ganhas ou perdidas -, os processos de inclusão ou exclusão de atores históricos, a percepção sobre o outro além da fronteira.

Pudemos constatar que não se pode dizer que a História Diplomática atual confunda-se com a história oficial. De toda forma, a denominação "História das Relações Internacionais" que a substitui para apontar 0 objetivo de realizar-se uma pesquisa mais abrangente não deve subtrair a importância da documentação diplomática. Reduzir o apego ao escrutínio documental e ao ambiente coevo em que se desdobram os processos políticos na intenção de ampliar o nível de análise seria, fundamentalmente, uma alavancagem ilusória do conhecimento historiográfico, implicando perda da qualidade da pesquisa. A investigação de fontes governamentais é parte essencial para que se compreendam os processos atinentes às relações internacionais, que também têm a ver com processos sociais e econômicos, representações e percepções, 0 mundo das idéias e as fontes que as nutrem.

Também chamamos a atenção para a existência de vários trabalhos que tratam da historiografia sobre as relações internacionais do Brasil, embora esteja clara a necessidade de um esforço maior e mais contínuo de reflexão sobre a área. $E$, nesse sentido, a "era da globalização" é notoriamente instigante, pelos desafios que representa, para buscar-se nova luz sobre os processos históricos particulares de construção do Estado nacional e das relações entre Estados nacionais. Entendemos que a pesquisa histórica realizada no Brasil nas duas últimas décadas mostra, de certa forma, que esse desafio tem sido enfrentado, ainda que tenha substancialmente a ganhar com a promoção de um maior diálogo entre a História das Relações Internacionais e o campo da Teoria da História e da H istória do Brasil. 
BREDA DOS SANTOS, Norma. History of International Relations in Brazil: A Summarize Field Evaluation. História, São Paulo, v.24, n.1, p.11-39, 2005.

ABSTRACT: This article proposes a reflection on the field of the History of International Relations, evaluating the specificity of its program of research and the characteristics is has acquired in Brazil. The study is composed of two main parts. The first one discusses the socio-intellectual delimitation of the field of History of International Relations and its academic institutionalization. The second part analyses the development of that area in Brazil and presents two arguments about this research field in the country during the last two decades. The first one is that the theoretical debates have modest repercussion in the area. The second one is that there is a relatively poor dialogue between historians of International Relations of Brazil and those who study the History of Brazil. The article intends to take into account the important discussions of theory and methodology as well as some particular themes of debate, as the illustrative treatment given to the question of nationality

KEYWORDS: Historiography; History of International Relations; diplomatic History

\section{NOTAS}

\footnotetext{
${ }^{1}$ Instituto de Relações Internacionais - Universidade de Brasília. CEP 70910900. Doutora pelo Institut de Hautes Études Internationales, Genebra, 1996. breda@unb.br.

Esta é uma versão bastante modificada do trabalho intitulado "Brazilian Historiography on International Relations: International Relations of Brazil and Brazilian Foreign Policy since 1990", apresentado em julho de 2005 no XX Congresso Internacional de Ciências Históricas, em Sidnei, Austrália, e no XXIII Simpósio da Associação Nacional de História (Anpuh), Londrina. Agradeço especialmente os comentários de Estevão Chaves R. Martins, José Otávio Nogueira e Gelson Fonseca à versão preliminar deste artigo.
} 
${ }^{2}$ SARAMAGO, José. História do cerco de Lisboa. São Paulo: Companhia das Letras, 1989, p.50.

3 HARTOG, Fançois. La France, Objet Historique. Le Monde des Débats, novembro, p.16, 2000.

${ }^{4}$ ACTON, Lectures on Modern History, 1906, p.318 apud CARR, E. H., Que é história? 8.ed. Rio de Janeiro: Paz e Terra, 2002, p.45.

${ }^{5}$ Em um dos melhores trabalhos de análise historiográfica, sobre a História do Brasil nos anos 80, seus autores, Carlos Fico e Ronald Polito, A História do Brasil (1980-1989): elementos para uma avaliação historiográfica. Ouro Preto, UFOP, 1992, p. 17, chamam a atenção para a dificuldade da empreitada: "Como se admite entre historiadores, a historiografia é um gênero considerado bastante complexo. Exige do analista conhecimentos de teoria, de metodologia e de História. Por outro lado, não será abusivo afirmar que há sempre o risco de este tipo de análise resvalar para o terreno da presunção, mormente se tudo não for feito a partir de parâmetros criteriosos que afastem qualquer possibilidade de pedantismo." Como anunciamos aqui a realização de um exercício infinitamente mais modesto, gostaríamos que este fosse beneficiado pela idéia de tratar-se apenas de um esforço inicial de problematização metateórica da atividade historiográfica, cuja sistematização ainda permanece incompleta.

${ }^{6}$ STEINER, Zara. On Writing International History: chaps, maps and much more. International Affairs, v.73, n.3, p.531-546, 1997.

${ }^{7}$ REMOND, René (org.). Por uma história política. Rio de janeiro: UFRJ, 1996. O livro foi publicado originalmente, em francês, em 1988.

${ }^{8}$ Sobre a especificidade e a renovação da história diplomática nos Estados Unidos, nas últimas duas décadas, ver MCMAHON, Robert J. Toward a Pluralist Vision: the study of American foreign relations as International History and National History. In: HOGAN, Michael J; PATERSON, Thomas G. Explaining the History of American foreign relations. New York/Cambridge, Cambridge University Press, 2004,

${ }^{9}$ A propósito, vale a observação de Francisco Falcon (1996) sobre "o fato de que a tendência da oficina de Clio, nestas últimas décadas, tem sido quase sempre a de legitimar o novo em função de sua novidade e de desqualificar o antigo apenas por ser velho ou tradicional. Tal tendência tem favorecido novidades reais e importantes mas tem também beneficiado pseudo-novidades e alguns modismos sem maior importância."

${ }^{10}$ IGGERS, Georg G. Historiography in the Twentieth Century: from scientific objectivity to the postmodern challenge, with a new epilogue. Middletown (Connecticut): Wesleyan University Press, 2005, p.153-154.

${ }^{11}$ FUKUYAMA, Francis. O Fim da História. Rio de Janeiro: Rocco, 1992.

${ }^{12}$ HUNTINGTON, Samuel. O Choque de Civilizações. Rio de Janeiro: Objetiva, 1996. 
${ }^{13}$ Idem, p.155 e 16 . No Brasil, a primeira edição de $O$ Fim da História é de 1992, e de O Choque de Civilizações, de 1997.

14 Iggers menciona a importância que tem tido para os pesquisadores, sobretudo europeus, a história local e nacional, e a necessidade de uma história global.

${ }^{15}$ Zara Steiner faz uma excelente síntese da história da disciplina no artigo já citado STEINER, Zara. Op. cit.

${ }^{16}$ HILL, Christopher. History and International Relations. In: SMITH, Steve (ed.). International Relations; British and American Perspectives. Oxford: Basil Blackw/British International Studies Association, 1985, p.127.

17 Desde 1974, o Institut Pierre Renouvin publica a revista Relations internationales, em conjunto com o Institut Universaire de Hautes Etudes Internationales, de Genebra (criado em 1927). Cf. CERVO, Amado Luiz. History of International Relations. In: International Encyclopedia of Social and Behavioral Sciences. Oxford: Elsevier, 2002, p.7824-7829.

${ }^{18}$ GIRAULT, René. Présentation. In: RENOUVIN, Pierre. Histoire des Relations Internationales. Du Moyen Age à 1789. v.I. Paris: Hachette, 1994, p.II.

${ }^{19}$ BOOTH, Ken. 75 Years on: Rewriting the Subject's Past - Reinventing its Future. In: SMITH, Steve; BOOTH, Ken; ZALEWSKI, Marisia (org.). International Theory: positivism \& beyond. Cambridge(UK): Cambridge University Press, p.328-339, 1996, p.328.

${ }^{20} \mathrm{O}$ livro do qual o capítulo de Booth faz parte, International Theory: Positivism E Beyond, foi publicado para comemorar os 75 anos do primeiro departamento de Política Internacional, considerado o "nascimento institucional" do campo de Relações Internacionais.

${ }^{21}$ HALLIDAY, Fred. Repensando as Relações Internacionais. Porto Alegre: UFRGS, 1999, p.21.

"Although Davies [doador dos fundos para a criação da cadeira Woodrow Wilson de Política Internacional] advocated the study of law, politics, ethics, economics, other civilisations and international organizations, what became lodged in the collective mind was the idea that the study of international politics, shocked into academic life by the Great War, must have the study of war as its overriding purpose". BOOTH, Ken. Op. cit. p.328.

22 Para ilustrar e confirmar a questão, é interessante conferir algumas definições dadas para o campo de estudo da História das Relações Internacionais em alguns de seus departamentos acadêmicos. Na Georgetown University é definido da seguinte forma: "The major in International History combines a broad introduction to the analysis of historical changes that transcend national boundaries with the opportunity to explore a particular theme or question in the context of a self-designed major concentration. The major goes beyond study of the formal relations between states - the traditional subject matter of diplomatic history - to address themes in social, cultural, and intellectual history. Historical scholarship today 
draws on ideas and data from subjects as varied as anthropology, philosophy, sociology, political science, religious studies, and literature, and this mix is reflected in the coursework for the International History major." Disponível em: $<<$ http://www3.georgetown.edu/sfs/bsfs/majors/ihis/ $>>$.

23 LIMA, Maria Regina Soares de. Teorias e Conceitos de Política Internacional. Rio de Janeiro: IUPERJ/UCAM, IRI/PUC-Rio. Mimeo, 2001.

24 ELMAN, Colin; ELMAN, Miriam F. Bridges and Boundaries: historians, political scientists and the study of international relations. Cambridge (MA): MIT Press, 2001, p.1.

${ }^{25}$ A propósito do tema, ver FALCON, Francisco, A Identidade do Historiador. Estudos Históricos, n.17, 1996, << <www.cpdoc.fgv.br/revista/arq/183.pdf $>>$.

${ }^{26}$ ELMAN, Colin; ELMAN, Miriam F. Op. cit., p.6-7.

27 O livro de Colin Elman e Miriam Elman contempla o diálogo entre historiadores que trabalham com história diplomática e os teóricos das relações internacionais. Foi organizado a partir da conferência "Diplomatic History and Internacional Relations Theory: Respecting Differences and Crossing Bounderies", realizado em 1998, sendo também tributário de um simpósio realizado pela revista International Security, realizado em 1997. No mesmo ano, a revista publicou sete artigos sobre o tema. Ver International Security, v.22, n.1. No livro Bridges and Boundaries ... há capítulos escritos por estudiosos bastante conhecidos e citados de forma muito recorrente na academia brasileira, como Stephen D. Krasner, John Lewis Gaddis e Robert Jervis.

${ }^{28}$ Sobre o sistema de causalidades, é importante mencionar as considerações de Jack S. Levy, Explaning Events and Developing Theories: History, Political Science, and the Analysis of International Relations, In: ELMAN, Colin e ELMAN, Miriam F. Op. cit., p.71-78, com relação aos problemas e limitações da distinção aqui adotada.

${ }^{29}$ A título de exemplo, ver ALMEIDA, Paulo Roberto. Estudos de relações internacionais do Brasil: Etapas da Produção Historiográfica Brasileira, 19271992. Revista brasileira de Política Internacional, n.1, p.11-36, 1993; BARROS, Alexandre. El Estudio de las Relaciones Internacionales en Brasil. In: PERINA, Rubén (org.). El estudio de las Relaciones Internacionales en America Latina y el Caribe. Buenos Aires: Grupo Editor Latinoamericano, p.49-69, 1985; BREDA DOS SANTOS, Norma. A Dimensão Multilateral da Política Externa Brasileira: o Perfil da Produção Bibliográfica. Revista brasileira de política internacional, n.2, 2002. Disponível em: <<www.relnet.com.br >>; CERVO, Amado Luiz. A Historiografia Brasileira das Relações Internacionais. Revista Interamericana de Bibliografia, v.42, n.3, p.393-409, 1992. Introdução à História das Relações Internacionais do Brasil. In: CERVO, Amado Luiz (org.). O Desafio Internacional. Brasília: UnB, 1994, p.9-58; CHEIBUB, Zairo B. Bibliografia Brasileira de Relações Internacionais e Política Externa, 1930- 
1980. Rio de Janeiro: IUPERJ, mimeo, 1981; FONSECA JR., Gelson. Diplomacia e Academia: um estudo sobre as análises acadêmicas sobre a política externa brasileira na década de 70 e sobre as relações entre o Itamaraty e a Comunidade Acadêmica. Brasília: Instituto Rio Branco. Tese do Curso de Altos Estudos, 1981; "Estudos sobre Política Externa no Brasil: os Tempos Recentes (1950-1980)". In: FONSECA JR, Gelson; LEÃO, Valdemar Carneiro (orgs.). Temas de Política Externa Brasileira. Brasília/São Paulo: Fundação Alexandre de Gusmão/Ática, 1989, p.275-283; HERZ, Mônica. O crescimento da área de relações internacionais no Brasil. Contexto internacional, v.24, n.1, p.7-40, 2002; LIMA, Maria Regina Soares de; CHEIBUB, Zairo Borges. Relações Internacionais e Política Externa Brasileira: debate intelectual e produção acadêmica. Rio de Janeiro: MRE/IUPERJ, mimeo, 1983; MYIAMOTO, Shiguenoli. O estudo das Relações Internacionais no Brasil: o Estado da Arte, Revista de Sociologia e Política, n.12, p.83-99, 1999.

${ }^{30}$ Jurandir Malerba, Notas à margem: a crítica historiográfica no Brasil dos anos 1990". Textos de História, v.10, n.1/2, 2002, trata do que denomina de "lampejo de esforço no sentido da profissionalização" da prática de crítica historiográfica dos anos 1990.

${ }^{31}$ De um lado, basta verificar que, à exceção de 2005, não tem existido nas reuniões bianuais da Associação Nacional de História (Anpuh) nenhum grupo de trabalho sobre história das relações internacionais, embora trabalhos na área possam ser encontrados em vários GTs. Por outro, nota-se que nos encontros anuais da Associação Nacional de Pós-Graduação e Pesquisa em Ciências Sociais (Anpocs), a área de relações internacionais tem sido mais claramente contemplada. Na lista de periódicos indexados na área de História pela Coordenação de Aperfeiçoamento de Nível Superior (CAPES/MEC), não há nenhum periódico que se dedique exclusivamente à história de relações internacionais. Há, no entanto, pelo menos dois periódicos em que a área é mais freqüentemente contemplada: a referida Revista Brasileira de Política Internacional e a revista eletrônica Cena Internacional, do Instituto de Relações Internacionais, da UnB. As revistas Contexto Internacional, do Instituto de Relações Internacionais (IRI) da PUC-Rio, Afro-Ásia, do Centro de Estudos Afro-Orientais (CEAO) da Universidade Federal da Bahia (UFBA), e Estudos Afro-Asiáticos, do Centro de Estudos Afro-Asiáticos, da Universidade Cândido Mendes. Vários outros periódicos contemplam periodicamente dossiês ligados a temas internacionais

32 ARRUDA, José J. e TENGARRINHA, José M. (1999), Historiografia LusoBrasileira Contemporânea. Bauru, Edusc, 1999, p.18.

33 LAMOUNIER, Bolívar e CARDOSO, Fernando Henrique (1978), A bibliografia de Ciência Política sobre o Brasil (1949-1974). Dados, n.18, p.3-32, 1978, p.25. José Honório Rodrigues foi diretor da Seção de Pesquisas do Instituto Rio Branco (1948-1951), cuja função principal é a formação dos 
diplomatas brasileiros, e professor do mesmo Instituto (1946 a 1956). Ver também IGLÉSIAS, Francisco. José (1988), "Honório Rodrigues e a Historiografia Brasileira”, Estudos históricos, n.1, 1988. Disponível em: $<<$ www.cpdoc.fgv.br/revista/arq/28.pdf $>>$.

${ }^{34}$ FICO, Carlos, POLITO, Ronald. (1996), "Teses e Dissertações de História Defendidas em 1995”, Estudos Históricos, $\mathrm{n}^{\circ}$ 17, 1996. Disponível em: $<<$ www.cpdoc.fgv.br/revista/arq/191.pdf $>>$.

35 O texto de JANCSÓ, István. A Construção dos Estados Nacionais na América Latina: Apontamentos para o Estudo do Império como Projeto In LAPA, José Roberto do Amaral; SZMRECSÁNYI, Tamás (orgs.). História Econômica da Independência e do Império. São Paulo: Hucitec, p.3-26, é seminal sobre o tema. Ver ainda COSTA, Wilma Peres (1995), A Espada de Dâmocles: o Exército, a Guerra do Paraguai e a Crise do Império. São Paulo: Hucitec, 1995, LAPA, J. R. do Amaral; SZMRECSÁNYI, Tamás (orgs.) (1996), Op. cit.; MAGNOLI, Demétrio (1997). O Corpo da Pátria. Imaginação Geográfica e Política Externa do Brasil. São Paulo: Moderna, 1997; PIMENTA, João Paulo G. Estado e Nação no Fim dos Impérios Ibéricos no Prata (1808-1828). São Paulo: Hucitec, 2002; e SANTOS, Luís Cláudio V. G. A Invenção do Brasil: o Império e o Interamericanismo: do Congresso do Panama a Conferência de Washington. Brasília, 2002. Tese de doutorado - UnB;

. O Brasil entre a Europa e a América: o Império e o interamericanismo (do Congresso do Panamá à Conferência de Washington). São Paulo: Unesp, 2004.

${ }^{36}$ FICO, Carlos, POLITO, Ronald. A História do Brasil (1980-1989): elementos para uma avaliação historiográfica. Ouro Preto: UFOP, 1992, p.31-36. A implantação dos programas de pós-graduação em História teve início em 1971 e foi na década de 70 que se estabeleceu a maior parte dos programas hoje existentes. Idem, p.33.

37 O Programa de Pós-Graduação em Relações Internacionais do Irel está organizado em duas áreas de concentração: história das relações internacionais e política internacional e comparada. Cf. www.unb.br/irel.

${ }^{38}$ FONSECA JR., Gelson. Diplomacia e Academia: um estudo sobre as análises acadêmicas sobre a política externa brasileira na década de 70 e sobre as relações entre o Itamaraty e a Comunidade Acadêmica. Brasília: Instituto Rio Branco. Tese do Curso de Altos Estudos, 1981, p.I.

${ }^{39}$ ALMEIDA, Paulo Roberto de. Op. cit., p.12.

${ }^{40}$ Segundo Almeida, "Calógeras representa quiçá o último elo dessa ligação entre a reflexão intelectual e a participação nos assuntos de Estado, e sua obra inaugura, precisamente, o ciclo profissional na história das relações internacionais do Brasil”. Idem, p.12.

${ }^{41}$ Idem, p. 14.

42 PANDIÁ CALÓGERAS, João. A política exterior do Império. 3.v. Rio de Janeiro: Imprensa Nacional, 1927-1928; VIANNA, Hélio. História Diplomática 
do Brasil. São Paulo: Melhoramentos, 1961; DELGADO DE CARVALHO, Carlos. História Diplomática do Brasil. Rio de Janeiro: Cia Editora Nacional, 1959; CERVO, Amado Luiz; BUENO, Clodoaldo. História da Política Exterior do Brasil. ed.rev. São Paulo: Ática, 2002 [1.ed. 1992].

${ }^{43}$ ALMEIDA, Paulo Roberto de. Op. cit. p.30-31.

${ }^{44}$ Ver JAGUARIBE, Hélio. Nacionalismo na Atualidade Brasileira. Rio de Janeiro: ISEB, 1958; LAFER, Celso. Uma Interpretação do Sistema de Relações Internacionais do Brasil. Revista Brasileira de Política Internacional, p.81-100, 1967.

${ }^{45}$ DE DECCA, Edgar, O Silêncio dos Vencidos. São Paulo: Brasiliense, 1981.

46 VISCARDI, Cláudia Maria R. O Teatro das Oligarquias: uma revisão da "política do café com leite". Belo Horizonte: C/Arte, 2000.

${ }^{47}$ Ver o excelente estudo de FRITSCH, Winston. Apogeu e crise na Primeira República: 1900-1930. In: ABREU, Marcelo de Paiva (org.) A ordem do Progresso. Cem anos de política econômica republicana, 1889-1989. Rio de Janeiro: Campus, p.31-79, 1990.

48 BREDA DOS SANTOS, Norma. Diplomacia e Fiasco - repensando a participação brasileira na Liga das Nações: elementos para uma nova interpretação. Revista Brasileira de Política Internacional, n.2, 2003. Disponível em: <<www.relnet.com.br $>>$

49 ABDENUR, Roberto. A Política Externa Brasileira e o "Sentimento de Exclusão”. In: FONSECA JR, Gelson; CASTRO, Sérgio Henrique Nabuco de (orgs.). Temas de política externa brasileira. São Paulo: Paz e Terra, t.II, v.1., p.3146, 1994.

${ }^{50}$ Idem, p.34.

${ }^{51}$ SANTOS, Luís Cláudio Villafañe dos. O Brasil entre a Europa e a América: o Império e o Interamericanismo. São Paulo: Unesp, 2004. O livro está baseado na tese de doutorado do autor, defendida no Programa de Pós-Graduação em História, Universidade de Brasília. SANTOS, Luís Cláudio Villafañe dos. $O p$. cit., 2002.

${ }^{52}$ SANTOS, Luís Cláudio Villafañe dos. O Brasil entre a Europa e a América: o Império e o Interamericanismo. São Paulo: Unesp, 2004, p.28.

Artigo recebido em 04/2006. Aprovado em 05/2006. 